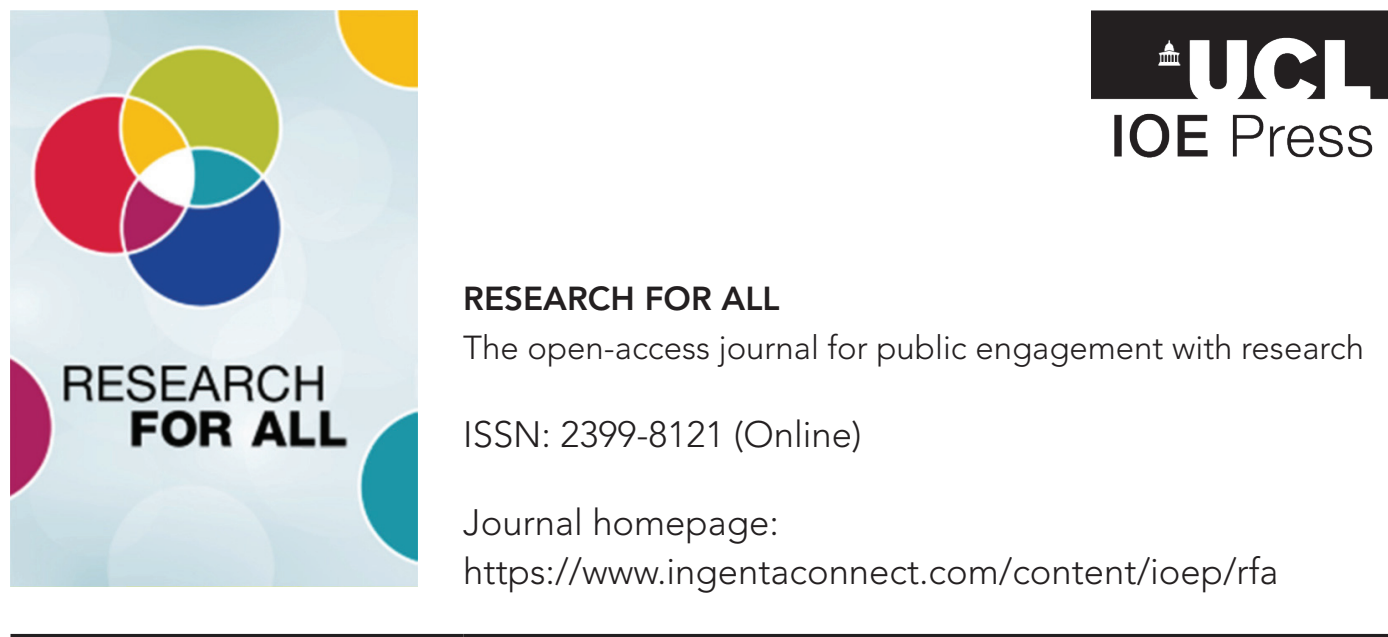

\title{
Editorial: Time for sharing knowledge
}

Sandy Oliver (D) and Sophie Duncan (D)

\section{How to cite this article}

Oliver, S. and Duncan, S. (2020) 'Editorial: Time for sharing knowledge'. Research for All, 4 (1): 1-5. DOI https://doi.org/10.18546/RFA.04.1.01

Publication date: 1 February 2020

\section{Copyright}

(C) Copyright 2020 Oliver and Duncan. This is an Open Access article distributed under the terms of the Creative Commons Attribution Licence (CC BY) 4.0 https://creativecommons.org/licenses/by/4.0/, which permits unrestricted use, distribution and reproduction in any medium, provided the original author and source are credited.

\section{Open access}

Research for All is a peer-reviewed open-access journal. 


\title{
Editorial: Time for sharing knowledge
}

\author{
Sandy Oliver* - UCL Institute of Education, UK \\ Sophie Duncan** - National Co-ordinating Centre for Public Engagement, UK
}

Research for All serves authors and readers who have a strong interest in different ways of knowing, and we have already discussed the language and writing styles adopted by authors sharing their perspectives (Oliver and Duncan, 2018). Here, we consider the investment of time required for the task of understanding and sharing orally different ways of knowing. Academic knowledge develops through formal studies to offer new ideas and theoretical understanding supported by empirical observations and codified analyses of how entities relate to each other - how the world generally fits together. More often, our understanding is not of the world generally, but of where or how we live in particular. We rely on our implicit understanding of local issues based on impressions and priorities, about how things are done by individuals and organizations, and changes over time. We tend to navigate our day-to-day personal lives by relying on tacit knowledge accrued through experience and familiarity with our immediate surroundings. Academics are steeped in planned observation and systematic analysis, many community organizations are steeped in change making, and schoolteachers and public engagement professionals (both feature in this issue) rely on valuable communication 'know how'. We all have different windows through which we make sense of the bigger picture.

No way of knowing is sufficient alone, and they are often intertwined. Whether we appreciate popular or classical music, we rely on technology to hear it at home. Science helps us understand a balanced diet, while culinary arts and social interactions make meals appealing. The stars on a clear night may evoke our wonder, but it is astronomy that satisfies our curiosity. Although daily events may be underpinned by knowledge coming simultaneously from the natural sciences, social sciences, and arts and humanities, academics have to make a concerted effort to reach beyond their discipline or beyond academia altogether.

This issue of Research for All includes articles that take imaginative approaches to crossing boundaries between different sets of knowledge or different groups of people. A common theme across these articles is the time required to understand or combine these different ways of knowing. This includes time for asking questions, time for reflection and assimilating new understandings, time for listening deeply and being prepared to change our views, and time for making thoughtful contributions.

Two articles describe reaching out to audiences who rarely engage with science, either for social or disability reasons. Woolman took science to a campsite to reach a sector of society who were not actively engaged with science, while Appleby et al. took science to students whose visual impairment presented a barrier to the 'communication of the science [that] is predominantly delivered using visual methods, often using pictures, conventional diagrams and other graphics'. Both these articles emphasize the importance of first understanding the world of those you want to engage - before deciding how to engage with them. Both articles make clear the time required of both the scientists and their audiences for mutual learning to take place. Woolman invested time in finding a partner with local knowledge to identify a promising site, and then 
found a promising season and time of day to attract newcomers to science. The choice of a campsite rather than a shopping centre seemed to work well, with people more willing to hang around and, having been attracted by the 'eww' factor of eating insects, keen to ask questions and talk about the science of sustainable food sources.

Appleby invested significant time in understanding a potential audience with visual impairment. Particle physicists often rely on presenting their results visually, to aid understanding. Overcoming this barrier began by the scientists investing considerable time in understanding how students with visual impairment learn and 'how best to engage with the audience on their terms'. Transforming means of communication with school students from the visual to the tactile was a step into the unknown for all involved. It involved students with visual impairment, their teachers and scientists working together in an iterative loop to design equipment and then to train teachers to enable new audiences to engage with particle physics for the first time.

While the previous two articles took the science out of academia, our next two invited others into academia to engage with clinical trials. Lea reflects on her experience as a member of a research team chosen for her experience of living with the health condition under investigation. In this dual role she has to understand both the research process and the lived experience of fellow patients. More than this, she and her peers have to put into words their understanding of patients' tacit knowledge to challenge the research team: as one put it, 'not being afraid to open my mouth. Not being afraid to use my experiences ... Challenging the researchers to rethink ... the process from a patient and carer's point of view'. Indeed, convening a group, overcoming differences between group members, finding ways of working together and then getting on with it all takes time. These are common challenges described by Tuckman (1965; Tuckman and Jensen, 1977) as successive stages of developing a group: forming, storming, norming and performing. Lea had encountered each stage by three-quarters of the way through a two-year clinical trial. She remembers: the challenge of recruiting and retaining group members; a 'stormy sea of multiple opinions'; the need to specify roles, terms of reference and a code of conduct; and, eventually, a research team more sensitive to how living with mental ill health can be disabling.

The importance of 'honest and open communication' was also noted by Sheridan et al. when devising digital and multimedia ways of talking about clinical trials with young people and their families. Not only did these resources need to convey the study accurately, but they also had to be intuitive to use by the young people and families, thereby combining knowledge based on science with understanding based on lived experience. Again, this took time: time for meetings, time for travel and time for reviewing documentation. Time could be chosen for convenience (daytime or evening), bought at an hourly rate, or reduced by holding meetings virtually, with the challenge that this might then compromise communication. These are not trivial decisions. Theoretical understanding and empirical evidence show how such decisions influence how well committees share and weigh up ideas together before making decisions. Sufficient time is required for 'all relevant knowledge to be shared and evaluated through discussion, especially when judgements need to be made by committees with members who vary in status' [emphasis added] (Oliver et al., 2018: n.p.).

Two articles sought to develop more collaborative ways of doing research, focusing on personal or community heritage. Allwork tapped local memories by convening workshops across England to uncover hidden histories of the First World War, histories kept alive by community groups and only revealed after time was invested in building trusting relationships between universities and communities. 
Once revealed, these histories challenge mainstream representations of history. Hoult et al. investigated the life trajectories of women with Pakistani heritage with the help of poetry to 'say the unsayable' and share 'subjective testimony' coherently, rather than take the heart out of data and lose much of their meaning through intellectual analysis.

Navigating these different ways of knowing is a valuable skill, and the three remaining papers address how these skills can be developed. Brookfield and Parker describe a programme for developing schoolteachers' skills and confidence to teach their Baccalaureate students how to make use of quantitative data - a programme that develops the art and science of teaching. This is a core need, as decisions about who teaches the qualification are informed by the practicalities of timetabling, so that some teachers prepare students without being familiar or confident with the numerical skills they need. Spurrell and Grace took the complementary approach of developing a 'new training programme to better equip university researchers to engage with and create interactive activities for schools'. Featherstone and Owen consider the breadth of activities that help public engagement professionals in universities gain confidence, experience and competence through workshops, coaching, opportunities for innovation or practice, peer-to-peer support and 'just in time' learning.

When asked what the main barrier to engaging the public was, researchers most cited time (Burchell et al., 2017). Community partners working with universities often cite that it is the time required for the work that had been underestimated, and underresourced. The articles in this issue explore the different facets of time that influence the success of engagement. They illustrate how, in order to share knowledge, time has to be made or found that suits the rhythm of people's lives to allow them to meet at all. Once together, the time has to be well managed to enable participants to share their ideas and work together productively. Time also has to be well managed between meetings to support the development of fruitful partnerships.

The articles in this issue tell us that investing in time and managing it well, so 'valuing the time taken to cultivate relationships' (Duncan and Oliver, 2019: 127), can ultimately lead to new ways of knowing, and doing.

\section{Articles in this issue}

Allwork, L. (2020) '"Sedimented histories" and "embodied legacies": Creating an evaluative framework for understanding public engagement with the First World War'. Research for All, 4 (1): 66-86. DOI https://doi.org/10.18546/RFA.04.1.06

Appleby, R.B., Edmonds, C.S. and Watson, R. (2020) 'Tactile Collider: A new approach to the communication of fundamental science to visually impaired people'. Research for All, 4 (1): 16-32. DOI https://doi.org/10.18546/RFA.04.1.03

Brookfield, C. and Parker, S. (2020) 'Improving the quantitative research skills of Welsh Baccalaureate teachers through university engagement'. Research for All, 4 (1): 102-16. DOI https://doi.org/10.18546/RFA.04.1.08

Featherstone, H. and Owen, D. (2020) 'Rethinking professional development for public engagement with research: A way to improve uptake and impact of training?'. Research for All, 4 (1): 128-44. DOl https://doi.org/10.18546/RFA.04.1.10

Hoult, E.C., Mort, H., Pahl, K. and Rasool, Z. (2020) 'Poetry as method - trying to see the world differently'. Research for All, 4 (1): 87-101. DOI https://doi.org/10.18546/RFA.04.1.07

Lea, L., Byford, S., Coney, Y., Crane, R., Fagabemi, N., Gurney, T., Leigh-Phippard, H., Rosten, C., Simms, K. and Strauss, C. (2020) 'Reflections on my role as a mental health service user co-applicant in a randomized control trial'. Research for All, 4 (1): 33-46. DOI https://doi.org/10.18546/RFA.04.1.04

Sheridan, R., Preston, J., Stones, S., Ainsworth, S., Taylor, D.H., Challinor, R., Ainsworth, S., Martin-Kerry, J., Brady, L.-M. and Knapp, P. (2020) 'Patient and public involvement in a study of multimedia clinical trial information for children, young people and families'. Research for All, 4 (1): 47-65. DOI https://doi.org/10.18546/RFA.04.1.05 
Spurrell, J. and Grace, M. (2020) 'A collaborative approach to schools engagement training for university staff'. Research for All, 4 (1): 117-27. DOI https://doi.org/10.18546/RFA.04.1.09

Woolman, A. (2020) 'Reaching non-specialist audiences and engaging them with science at an affordable seaside campsite'. Research for All, 4 (1): 6-15.

DOI https://doi.org/10.18546/RFA.04.1.02

\section{Acknowledgements}

Research for All is a collaborative project that relies on a range of associate editors with experience of engaged research in a variety of contexts. The associate editors who advised us on the content for this issue of the journal are:

- Ceri Davies - University of Brighton, UK

- Jude Fransman - Open University, UK

- Jamie Gallagher - University of Glasgow, UK

- Ann-Marie Houghton - University of Lancaster, UK

- Lorraine Mclllrath - NUI Galway, Ireland

- Emma McKenna - Queen's University Belfast, UK

- Anne Rathbone - BoingBoing, UK

- Allison Tong - University of Sydney, Australia

We extend our thanks to them and to all the expert reviewers - two for each contribution - who helped us guide authors towards their final drafts.

\section{References}

Burchell, K., Sheppard, C. and Chambers, J. (2017) 'A "work in progress"? UK researchers and participation in public engagement'. Research for All, 1 (1), 198-224.

Duncan, S. and Oliver, S. (2019) 'Editorial: The humanity of engagement at the core of developing and sharing knowledge'. Research for All, 3 (2), 125-8.

Oliver, S. and Duncan, S. (2018) 'Editorial: The challenges of sharing different ways of knowing'. Research for All, 2 (1), 1-5.

Oliver, S., Hollingworth, K., Briner, R., Swann, C., Hinds, K. and Roche, C. (2018) 'Effective and efficient committee work: A systematic overview of multidisciplinary literatures'. Evidence Base, 2, 1-21.

Tuckman, B.W. (1965) 'Developmental sequence in small groups'. Psychological Bulletin, 63 (6), 384-99.

Tuckman, B.W. and Jensen, M.A.C. (1977) 'Stages of small-group development revisited'. Group and Organization Studies, 2 (4), 419-27. 